\title{
Estudo da eficiência de pavimentos permeáveis: análise da permeabilidade e das propriedades mecânicas
}

\begin{abstract}
Nos últimos tempos, as cidades têm apresentado crescimento acelerado que muitas vezes ocorre sem um planejamento adequado, resultando na ocupação inadequada do solo e provocando diversos problemas socioambientais, dentre eles as enchentes. Tecnologias têm sido desenvolvidas para minimizar tais impactos devido a impermeabilização do solo, como é o caso do pavimento permeável de concreto, que apresenta uma solução no auxílio dos sistemas de drenagem urbana. Torna-se necessário verificar a eficiência desse material baseado nos estudos sobre suas características físicas enas suas condições de aplicação. No Brasil, embora já exista uma norma que especifique as características exigidas para a utilização desse pavimento, ainda não há um estudo aprofundado sobre a dosagem que permite que as peças de concreto cumpram as imposições. Diante disso, a seguinte proposta objetivou testar diferentes traços para confeç̧ão de um concreto permeável e verificar suas características quanto à resistência mecânica e à permeabilidade. Foram estabelecidas como variáveis de controle: 2 variações de confecção de um concreto permeável e verificar suas características quanto à resistência mecânica e à permeabilidade. Foram estabelecidas como variáveis de controle: 2 variações de confeccionados corpos de prova cilíndricos e prismáticos, que foram ensaiados conforme NBR's específicas. A partir dos resultados obtidos constatou-se que o traço com melhor resistência mecânica foi o traço 1, moldado com a mistura entre as britas 0 e 1 , apresentando apenas $5 \%$ do agregado miúdo calculado em sua composição; porém, mesmo obtendo os melhores resultados, o valor mínimo de resistência a compressão axial não foi atingido. Quanto a permeabilidade, todos os traços apresentaram bons resultados. Os traços 1 e 3 (ambos com areia na composição) se apresentaram como os mais adequados para utilização em passeios urbanos, pisos internos, praças, quadras poliesportivas descobertas, ciclovias e até mesmo estacionamentos de veículos leves devido a boa permeabilidade, mas ainda não foram considerados aptos para utilização em pavimentos liberados ao tráfego de veículos.
\end{abstract}

Palavras-chave: Concreto autodrenante; Resistência; Aplicabilidade.

\section{Study of the efficiency of permeable floors: analysis of permeability and mechanical properties}

\begin{abstract}
In recent times, cities have experienced rapid growth that often occurs without proper planning, resulting in improper land occupation and causing several socio-environmental problems, including floods. Technologies have been developed to minimize these impacts due to soil waterproofing, as is the case with the permeable concrete pavement, which presents a solution to help urban drainage systems. It becomes necessary to check the efficiency of this material based on studies on its physical characteristics and conditions of application. In Brazil, although there is already a standard that specifies the characteristics required for the use of permeable concrete, there is still no in-depth study on the dosage of materials that makes the concrete pieces meet the requirements. Therefore, the following proposal aimed to test different recipe for the manufacture of permeable concrete and verify their characteristics in relation to the pieces meet the requirements. Therefore, the following proposal aimed to test different recipe for the manufacture of permeable concrete and verify their characteristics in relation to the
mechanical resistance and permeability. Control variables were established: 2 variations of coarse aggregate (mixture between sizes $9.5 \mathrm{~mm}$ and $19 \mathrm{~mm}$, and only $19 \mathrm{~mm}$ ), and 3 variations of fine aggregate percentage ( $0 \%, 5 \%$ and $10 \%)$. To carry out the study, cylindrical and prismatic samples were made, which were tested according to specific NBRs. From the results obtained, it was found that the line with the best mechanical resistance was line 1 , molded with the mixture between gravel 0 and 1 , and presenting only $5 \%$ of the fine aggregate calculated in it composition; however, even obtaining the best results, the minimum value of axial compression resistance has not been reached. Traces 1 and 3 (both with sand in the trace) were the most suitable for use on urban sidewalks, indoor floors, squares, uncovered sports courts, bike lanes and even light vehicle parking due to good permeability, but they have not been yet considered suitable for use in flooring released for vehicular traffic.
\end{abstract}

Keywords: Self-draining concrete; Resistance; Applicability.

Reviewed anonymously in the process of blind peer.

Maria Ingridy Lacerda Diniz (D)

Universidade Federal da Paraíba, Brasil http://lattes.cnpq.br/6066833739529461 http://orcid.org/0000-0002-8574-7888

mariaingridydiniz@gmail.com

\section{Alan Barbosa Cavalcanti (iD}

Universidade Federal da Paraíba, Brasil http://lattes.cnpq.br/5910031792518971 http://orcid.org/0000-0002-2146-4950 profalancavalcanti@gmail.com

Cinthia Maria de Abreu Claudino (iD) Universidade Federal da Paraíba, Brasil http://lattes.cnpq.br/9722533812780740 http://orcid.org/0000-0003-4233-6082 cinthiamariaac@gmail.com
Thiago de Sá Sena (iD)

Universidade Federal de Campina Grande, Brasil http://lattes.cnpq.br/7172038975336416 http://orcid.org/0000-0003-1593-3439

engthiagosena@gmail.com

Raquel Ferreira do Nascimento (iD)

Universidade Federal do Rio Grande do Norte, Brasil http://lattes.cnpq.br/6299630411846009 http://orcid.org/0000-0001-5376-9364 raquelfn96@hotmail.com

Camila Gonçalves Luz Nunes

Universidade Federal da Paraíba, Brasil http://lattes.cnpq.br/6724820881976042 camilanunes.engcivil@hotmail.com
Daniel Costa da Silva

Universidade Federal da Paraíba, Brasil

http://lattes.cnpq.br/0127405083385505 daniel.costa.silva@hotmail.com

Pedro Henrique dos Santos Pereira Universidade Federal da Paraíba, Brasil http://lattes.cnpq.br/6348663934044404 pedrohenrique.96ph@gmail.com

\section{Lucas Moura Delfino}

Universidade Federal da Paraíba, Brasil http://lattes.cnpq.br/4922835126288442 http://orcid.org/0000-0003-4940-2249

lucasmouragba@hotmail.com c

DOI: 10.6008/CBPC2179-6858.2021.003.0032
Referencing this:

DINIZ, M. I. L.; CAVALCANTI, A. B.; CLAUDINO, C. M. A.; SENA, T. S.; NASCIMENTO, R. F.; NUNES, C. G. L.; SILVA, D. C.; PEREIRA, P. H. S.; DELFINO, L. M.. Estudo da eficiência de pavimentos permeáveis: análise da permeabilidade e das propriedades mecânicas. Revista Ibero Americana de Ciências Ambientais, v.12, n.3, p.398-407, 2021. DOI: http://doi.org/10.6008/CBPC2179-6858.2021.003.0032 


\section{INTRODUÇÃO}

A crescente ocupação urbana associada à sua falta de planejamento vem provocando um aumento das superfícies impermeabilizadas, como construção de edificações, áreas pavimentadas e até mesmo estacionamentos, que por sua vez, provocam a diminuição da infiltração da água do solo, o que aumenta os riscos da erosão devido a remoção das camadas vegetais superficiais, maior velocidade de escoamento e alagamentos das ruas (SANTOS et al., 2017). A redução da absorção natural do solo provoca a diminuição do Tempo de Concentração (Tc) da água no sistema de drenagem. Esse processo intensifica os danos em períodos de cheia e o tempo de drenagem ou direcionamento das águas para os reservatórios/rios diminui, o que pode acarretar enchentes (TARGA et al., 2012).

A partir desse contexto, é viável o estudo de novas tecnologias que auxiliem na solução desses problemas, e uma delas é a utilização de concretos permeáveis em áreas urbanas estratégicas, com o intuito de auxiliar a recuperação da capacidade de infiltração do solo que vem sendo perdida com o avanço das áreas urbanas, auxiliando no processo de drenagem.

O Brasil publicou a primeira norma sobre os requisitos necessários para aplicação desse material, a NBR 16416 (ABNT, 2015) - Pavimentos Permeáveis de Concreto - Requisitos e Procedimentos. No entanto, em seu conteúdo não existe informações sobre a dosagem ou sugestão de traço para que a mistura atenda aos requisitos apresentados no documento, deixando uma lacuna a ser preenchida por pesquisadores sobre encontrar as quantidades e o método ideal para a fabricação de peças de concreto autodrenantes que atendam às exigências quanto a resistência e a permeabilidade.

O concreto permeável, segundo Batezini (2013), consiste em uma estrutura que permite a passagem da água por meio de suas camadas, absorvendo parcial ou totalmente o escoamento a partir de sua superfície permeável. Ainda é possível redirecionar a água infiltrada para um reservatório específico, ou apenas permitir que ela seja absorvida pelo solo. No Brasil, os estudos para averiguar a eficácia e aplicabilidade destas estruturas para a redução dos impactos das cheias ainda é insuficiente, contando com poucos trabalhos publicados acerca do tema, principalmente no quesito resistência.

Já no cenário internacional, o pavimento autodrenante vem recebendo investimentos de vários países, como por exemplo a Alemanha e o Japão, que já fazem uso da água de chuva drenada para fins não potáveis, e não apenas para utilidade doméstica. Seus benefícios são do interesse público devido a sua aplicabilidade em zonas urbanas, como o ganho ambiental e econômico onde o valor de terra é elevado (HANSEN et al., 1996, citado por SANTOS et al., 2017).

Diante da problemática, este trabalho visou avaliar quatro tipos de traços para a mistura do concreto permeável, com o intuito de estudar suas características mecânicas e verificar o cumprimento das exigências mínimas para usos distintos, associada a maior permeabilidade. Acredita-se que a partir de estudos com esse objetivo seja possível definir as condições de aplicação para cada traço de concreto permeável. 


\section{REVISÃO TEÓRICA}

Atualmente, o concreto permeável tem se apresentado um tipo pertinente de pavimento devido à sua eficiência em permitir que a água flua através de si, sendo capaz de reabastecer as águas subterrâneas e reduzir o escoamento das águas pluviais (SUMANASOORIYA et al., 2011; BU et al., 2018).

A utilização do concreto permeável pode ser considerada algo contemporâneo no Brasil. No entanto, tal procedimento já é utilizado a muito mais tempo por diversos outros países. Na década de 1970, os pavimentos porosos começaram a ser estudados nos Estados Unidos da América, com o intuito de conter o fenômeno da hidroplanagem e reduzir o ruído provocado durante a circulação dos veículos, porém tais estudos foram ignorados por certo período. Tempos depois, as pesquisas foram retomadas devido a problemática hídrica da Florida e em parte dos estados do Sudeste estadunidense. Agora, os pavimentos porosos se apresentaram como uma solução para redução dos altos coeficientes de escoamento superficiais oriundos do processo de impermeabilização das vias urbanas. No fim da década em questão, o ponto principal do estudo, do agora conhecido como pervius concrete, era sua capacidade de infiltração (BOTTEON, 2017).

Segundo Oliveira (2003), as primeiras aplicações do concreto poroso no Brasil foram em aeroportos em Belo Horizonte - MG e no Rio de Janeiro, a exemplo do aeroporto Santos Dumont, que em 1987 foi recapeado com revestimento asfáltico drenante. Já a aplicação do concreto em rodovias se iniciou no ano de 1992, apresentando trecho executado na rodovia de Bananeiras - SP, e em seguida com trecho na extensão da marginal da Rodovia Presidente Dutra. No ano 2000, foram construídos 33,5 km de asfalto autodrenante na duplicação da Rodovia BA-099 e também em Santa Catarina em trecho da Rodovia BR-101.

Uma das cidades brasileiras que é vítima continuamente dos problemas de alagamentos e enchentes a grande São Paulo. No ano de 2006 foram lançados empreendimentos para criar calçadas porosas e, em 2007, que os edifícios construíssem reservatórios que acumulassem as águas da chuva. No entanto, o emprego dos pavimentos porosos continua bastante restrito, mesmo que entre 2005 e 2007 a prefeitura municipal tenha construído cerca de $350 \mathrm{~km}$ de calçadas permeáveis, esse total ainda equivale a apenas $1 \%$ da quilometragem de passeios da cidade.

Logo, é notório que a aplicação do pavimento poroso apresenta benefícios nos casos de impermeabilização não planejada do solo, no entanto existem dificuldades que ainda precisam ser superadas para que sua aplicação seja disseminada de fato, como a resistência do material ao tráfego. Devido à grande quantidade de vazios intencional na própria estrutura das peças de concreto, a resistência estática do concreto permeável é menor do que o concreto convencional (BU et al., 2018).

No entanto, quanto mais alta porosidade é necessária, pouco ou nenhum agregado fino é adicionado à mistura. Assim, os agregados graúdos nas misturas são colados com camadas de pasta de cimento muito finas, em vez de incorporadas na pasta de cimento como no concreto normal (ZHONG et al., 2016; BU et al., 2018). 


\section{MATERIAIS E MÉTODOS}

\section{Materiais}

No trabalho em questão, foram considerados dois tamanhos diferentes de agregado graúdo, brita 0 (Tamanho Máximo Nominal - TMN - de 9,5mm) e brita 1 (TMN = 19mm). Já como agregado miúdo foi utilizada areia média, com diâmetro máximo característico de 2,4mm. O cimento utilizado foi do tipo CPII-Z32-RS e a água de amassamento apresentava as características exigidas para utilização em concreto dispostas na NBR 15900-1 (ABNT, 2009) - Água para amassamento do concreto - Parte 1: Requisitos.

\section{Caracterização dos Agregados}

De acordo com NBR NM 248 (ABNT, 2003), foram realizadas as análises granulométricas dos agregados (graúdos e miúdos) utilizados, para determinar as dimensões relativas das partículas que constituíam uma amostra. Para que se pudesse calcular os traços que seriam utilizados na pesquisa também foi necessário determinar a massa específica e a massa unitária dos agregados, realizados respectivamente de acordo com as normas NBR NM 52 (ABNT, 2003) e NBR NM 45 (ABNT, 2006).

\section{Composição dos Traços}

De acordo com a norma NBR 16416 (ABNT, 2015) - Pavimentos Permeáveis de Concreto, ainda não há um traço ideal para concretos permeáveis, deixando assim um leque de possibilidades para testes e pesquisas em busca do melhor traço, ou seja, aquele que apresente maior resistência associada a maior permeabilidade. Neste trabalho foram compostos 3 traços distintos determinados de diferentes maneiras, embasados em pesquisas bibliográficas e nos métodos de dosagem para concretos convencionais.

Em todas as misturas a relação água/cimento foi fixada no valor de 0,54. Esta medida foi tomada devido as variações de porcentagem de agregado miúdo e do diâmetro do agregado graúdo utilizado em cada mistura, e para evitar conclusões errôneas devido as alterações no fator, optou-se por fixá-lo.

\section{Traço 1}

O primeiro traço foi encontrado a partir de pesquisas de desempenho do concreto permeável. Em sua grande maioria, a proporção 1:4 (cimento:agregados) apresentou destaque. Neste caso, foi utilizada uma mistura entre as britas 0 e 1 , e reduziu-se ainda mais a porcentagem de areia na mistura, utilizando apena $5 \%$ da proporção geral de agregados.

$$
\begin{aligned}
\text { brita } 1 & =65 \% \\
1: 4 \rightarrow \text { brita } 0 & =20 \% \\
\text { areia } & =5 \%
\end{aligned}
$$

\section{Traço 2}

O segundo traço também foi encontrado seguindo as pesquisas do item 3.3.1. Neste caso optou-se por não utilizar porcentagem alguma de areia, com o intuito de testar se apenas os finos da combinação das 
britas apresentariam desempenho benéfico ao concreto e avaliar quais as consequências da não utilização de agregado miúdo na mistura. A proporção de agregados foi então dividida em porcentagens de uma mistura entre a brita 0 e a 1.

$$
1: 4 \rightarrow \begin{aligned}
& \text { brita } 1=70 \% \\
& \text { brita } 0=30 \%
\end{aligned}
$$

\section{Traço 3}

O terceiro traço foi determinado a partir do método convencional de dosagem ABCP. Optou-se por analisar o comportamento do concreto apenas com a utilização de $10 \%$ da massa de agregado miúdo calculada, com a intenção de aumentar o número de vazios existente. $O$ agregado graúdo utilizado foi apenas a brita 1 . O valor do traço encontrado foi de $1: 0,123: 2,95$.

\section{Moldagem e Cura}

Os procedimentos para moldagem e cura dos corpos de prova utilizados na pesquisa foram com base nas especificações da NBR 5738 (ABNT, 2015). Para os corpos de prova cilíndricos, foi adotado o método de compactação manual determinado pela mesma norma supracitada, que determina duas camadas com 12 golpes por camada para corpos de prova com dimensões $10 \times 20 \mathrm{~cm}$. Já para os corpos de prova prismáticos, que possuíam dimensão básica $d=150 \mathrm{~mm}$, foi adotado a compactação mecânica, com apenas uma camada como indicado em norma. Foi escolhida a cura úmida (submersa) para todos os corpos de prova.

\section{Ensaios Mecânicos}

\section{Compressão Axial}

O ensaio de compressão axial (Figura 1) foi realizado de acordo com a norma NBR 5739 (ABNT, 1994). Os CP's utilizados foram rompidos após um período de 28 dias em cura úmida. Em virtude das irregularidades dos topos dos corpos de prova, foram utilizados discos neoprene para auxiliar na distribuição de tensões nos CP's. As rupturas foram realizadas em triplicata, com exceção do Traço 3.

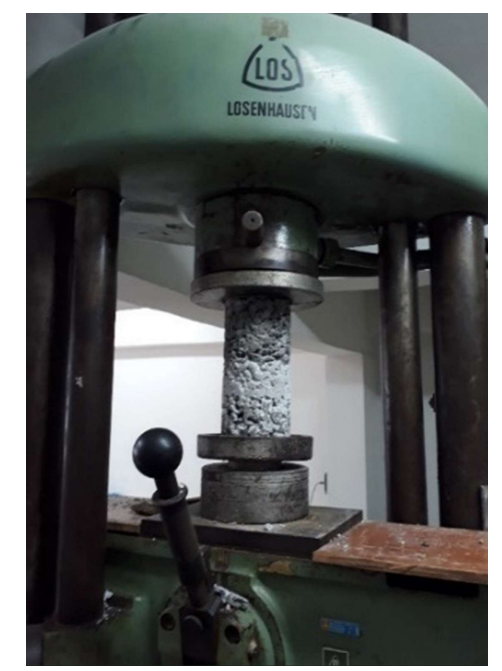

Figura 1: Ensaio de Compressão Axial. 


\section{Tração na Flexão}

O ensaio para a determinação da resistência à tração na flexão em corpos de prova prismáticos (Figura 2) foi realizado de acordo com a NBR 12142 (ABNT, 2010). As amostras utilizadas foram rompidas após um período de 28 dias em imersão, e calculadas a partir da Equação 1.

$$
f c t, f=\frac{F \cdot l}{b \cdot d^{2}}
$$

Onde:

fct,f: resistência à tração na flexão (MPa);

$\mathrm{F}$ : força máxima registrada na máquina de ensaio $(\mathrm{N})$;

$\mathrm{L}$ : dimensão do vão entre apoios $(\mathrm{mm})$, equivalente a $550 \mathrm{~mm}$;

b: largura média do corpo de prova $(\mathrm{mm})$, equivalente a $150 \mathrm{~mm}$; $\mathrm{d}$ : a altura média do corpo de prova $(\mathrm{mm})$, equivalente a $150 \mathrm{~mm}$.

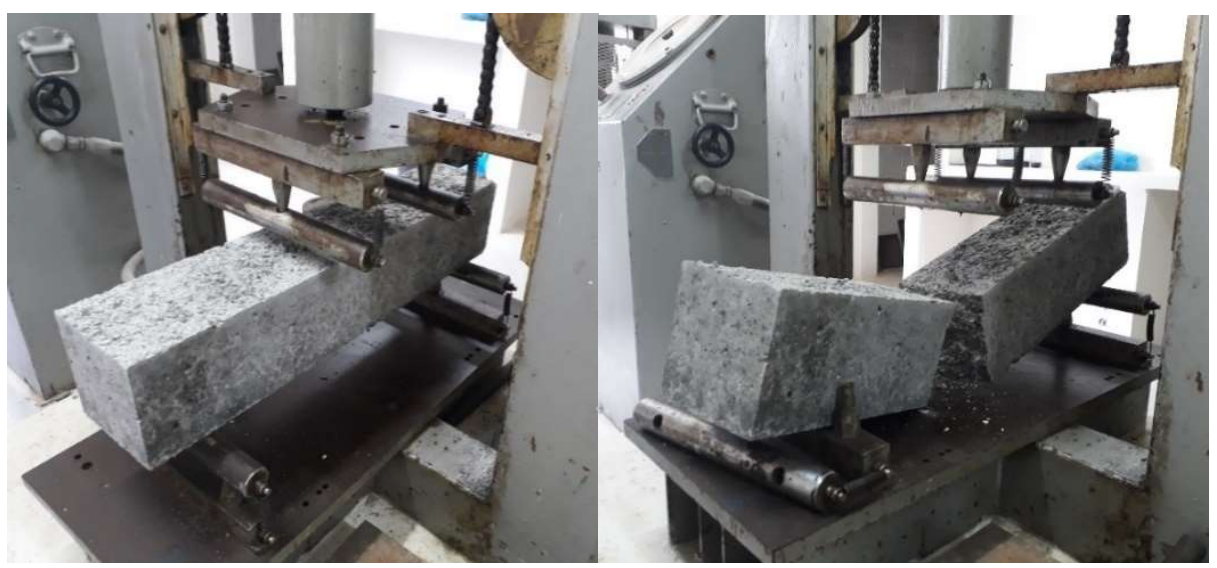

Figura 2: Ensaio de Tração na Flexão.

Destaca-se que a resistência à tração é uma das propriedades mais importantes relacionadas à resistência de pavimentos, uma vez que o esforço nestas peças possui uma solicitação maior na tração (PITTA, 1998). Uma grande dificuldade encontrada foi o processo de vibração do concreto nos moldes dos corpos de prova. Devido à pouca trabalhabilidade, mesmo com a lenta retirada do equipamento, houve a permanência de espaços vazios (Figura 3), o que provocou uma diminuição significativa na resistência à tração devido a existência de tais pontos críticos. A solução para o estudo seria optar pelo adensamento manual dos corpos de prova prismáticos.

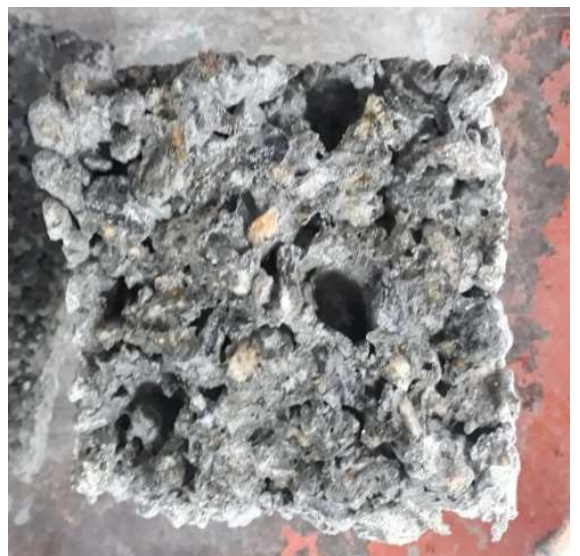

Figura 3: Detalhe do Interior do Corpo de Prova Rompido no Ensaio de Tração na Flexão. 


\section{Compressão Diametral}

Devido a impossibilidade de realizar o ensaio de tração na flexão no laboratório de estruturas da universidade em que o traço 3 foi preparado, foi utilizada a equação de Hammitt (1971) - Equação 2 - que correlaciona a resistência à tração na flexão relativa com a resistência à tração indireta por compressão diametral (Figura 4), para que fosse possível comparar os resultados obtidos do traço 4 com a norma.

$$
f c t, f=1,02 \cdot f c t, s p+1,48 \quad \text { Equação (2) }
$$

Onde:

$f c t, f$ : resistência à tração na flexão relativa (MPa); $f c t, s p$ : resistência à tração por compressão diametral (MPa).

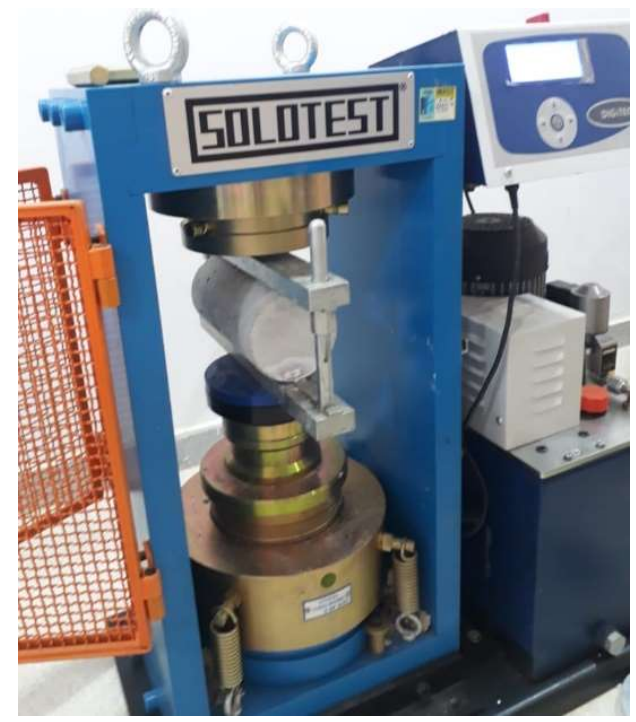

Figura 4: Ensaio de Compressão Diametral.

Este procedimento foi adotado para permitir uma comparação direta do traço 3 com os requisitos da NBR 16416 (ABNT, 2015) que especifica o valor mínimo, de 2 MPa, para a resistência à tração na flexão para concretos permeáveis.

O valor da resistência a compressão diametral foi calculado de acordo com a Equação 3, como exige a NBR $7222 / 2010$.

$$
f c t, s p=\frac{2 \cdot F}{\pi \cdot d \cdot l}
$$

Onde:

fct,sp: resistência à tração por compressão diametral, expressa com três algarismos significativos, em megapascals (MPa);

F: força máxima obtida no ensaio, expresso em newtons $(\mathrm{N})$; d: diâmetro do corpo de prova, expresso em milímetros ( $\mathrm{mm})$; I: comprimento do corpo de prova, expresso em milímetros ( $\mathrm{mm}$ ).

\section{Ensaio de Permeabilidade}

Para a realização do ensaio de permeabilidade nos corpos de prova em laboratório é recomendado utilizar um permeâmetro com carga hidráulica variável ou constante. Devido a não disponibilidade de um permeâmetro para que se pudesse realizar tal ensaio da maneira mais coerente, foi adotada a metodologia utilizada em campo para a verificação, que consistiu nos procedimentos disposto no Anexo A da NBR 16416 
(ABNT, 2015). Os resultados foram calculados de acordo com a Equação 4.

$$
k=\frac{C \cdot m}{\left(d^{2} \cdot t\right)}
$$

Equação (4)

Onde:

k: coeficiente de permeabilidade expresso em milímetros por hora $(\mathrm{mm} / \mathrm{h})$;

$\mathrm{m}$ : massa de água infiltrada expressa em quilogramas $(\mathrm{kg})$;

d: diâmetro interno do cilindro de infiltração expresso em milímetros ( $\mathrm{mm}$ );

t: tempo necessário para toda a água percolar expresso em segundos (s);

1'QW12C: fator de conversão de unidades do sistema SI, com valor igual a 4.583.666.000.

\section{RESULTADOS E DISCUSSÃO}

Os resultados obtidos a partir dos ensaios de compressão axial se encontram dispostos na Tabela 1.

Tabela 1: Resultados do Ensaio de Compressão Axial.

\begin{tabular}{|c|c|c|c|c|}
\hline & Corpo de Prova & Força aplicada (tf) & Resistência (MPa) & Média (MPa) \\
\hline \multirow{3}{*}{ Traço 1} & $\mathrm{CP} 1$ & 7,5 & 9,37 & \multirow{3}{*}{10,61} \\
\hline & $\mathrm{CP} 2$ & 6,5 & 8,12 & \\
\hline & CP3 & 11,5 & 14,36 & \\
\hline \multirow{3}{*}{ Traço 2} & CP3 & 7,1 & 8,87 & \multirow{3}{*}{8,49} \\
\hline & CP4 & 6,2 & 7,74 & \\
\hline & $\mathrm{CP} 2$ & 5,5 & 6,87 & \\
\hline \multirow{2}{*}{ Traço 3} & CP1 & 7,7 & 9,58 & \multirow{2}{*}{9,55} \\
\hline & $\mathrm{CP} 2$ & 7,6 & 9,53 & \\
\hline
\end{tabular}

O traço que obteve a maior resistência a compressão axial, atingindo uma média de 10,61 Mpa, foi o traço 1. Apesar dos traços não terem atingido o limite mínimo da norma NBR 16416 (ABNT, 2015) de 20 $\mathrm{MPa}$, este valor provavelmente poderia ser alcançado se utilizado aditivos superplastificantes, se fosse reduzida a relação água/cimento ou ainda com alteração dos traços e do empacotamento com a redução dos vazios, que acarretaria na diminuição da permeabilidade. Os resultados obtidos a partir dos ensaios de tração na flexão se encontram dispostos na Tabela 2.

Tabela 2: Resultados do Ensaio de Tração na Flexão.

\begin{tabular}{llll}
\hline Traço & Corpo de Prova & Força aplicada (N) & Resistência (MPa) \\
\hline 1 & CP6 & $58.839,9$ & 7,84 \\
\hline 2 & CP6 & $19.613,3$ & 2,61 \\
\hline
\end{tabular}

É possível verificar que todos os valores de resistência à tração na flexão obtidos, estão de acordo com a ABNT NBR 16416 (ABNT, 2015), a qual exige que a resistência mínima para concretos permeáveis moldados no local seja maior ou igual a $2 \mathrm{Mpa}$.

A areia em geral auxiliou no aumento da resistência à tração do concreto que apresentou resultados extremamente superiores aos traços sem a adição de areia. Em relação ao ensaio de compressão diametral, pôde-se obter os resultados dispostos na Tabela 3.

Tabela 3: Resultados do Ensaio de Compressão Diametral.

\begin{tabular}{llllllll}
\hline \multirow{2}{*}{ Traço } & $\begin{array}{l}\text { Corpo } \\
\text { Prova }\end{array}$ & de & $\begin{array}{l}\text { Força aplicada } \\
(\mathrm{N})\end{array}$ & $\begin{array}{l}\text { Resistência à Tração por } \\
\text { Diametral (MPa) }\end{array}$ & $\begin{array}{l}\text { Compressão } \\
\text { Resistência à Tração na }\end{array}$ & $\begin{array}{l}\text { Flexão } \\
\text { Relativa (MPa) }\end{array}$ & 3,93 \\
\hline \multirow{2}{*}{3} & CP4 & 75.920 & 2,41 & & 3,94 \\
\hline
\end{tabular}


O CP3 foi descartado do cálculo da média da resistência à tração do traço 3 devido a uma irregularidade da prensa. No entanto, os valores apresentados pelos demais corpos de prova não se apresentaram discrepantes, o que minimiza a possibilidade de erro do valor médio.

Devido ao bom resultado obtido utilizando a relação de Hammitt (1971), também foi verificada a diferença do valor encontrado pela relação para os demais traços. Os resultados obtidos pelo ensaio de compressão diametral dos traços 1 e 2 encontra-se na Tabela 4.

Tabela 4: Verificação do uso da relação de Hammitt (1971) para comparação dos resultados reais do ensaio de tração na flexão.

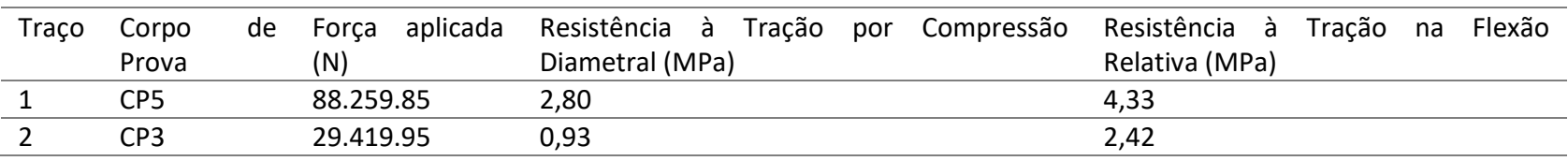

A diferença entre os valores encontrados utilizando a equação e os encontrados com o ensaio propriamente dito, podem ter ocorrido devido aos pontos críticos formados no momento da compactação mecânica dos corpos de prova prismáticos.

Já no quesito da permeabilidade, a média de tempo para o volume adentrar o corpo de prova bem como o valor do coeficiente de permeabilidade de cada traço, encontra-se na Tabela 5.

Tabela 5: Ensaio de Permeabilidade (método utilizado 'In Loco').

\begin{tabular}{|c|c|c|c|}
\hline Traço & Massa de água utilizada (Kg) & Média de Tempo Necessário (s) & Coeficiente de Permeabilidade $-\mathrm{K}(\mathrm{m} / \mathrm{s})$ \\
\hline 1 & \multirow{3}{*}{0,5} & 56 & $2,32 \times 10^{-3}$ \\
\hline 2 & & 120 & $1,08 \times 10^{-3}$ \\
\hline 3 & & 20 & $6,49 \times 10^{-3}$ \\
\hline
\end{tabular}

Alguns corpos de prova apresentaram material segregado no fundo devido ao processo de compactação, o que pode ter influenciado na adaptação do ensaio. No entanto, todos os traços se apresentaram dentro do valor mínimo de $\mathrm{k}=1 \times 10^{-3}$, especificado na ABNT NBR 16416 (ABNT, 2015).

\section{CONCLUSÕES}

Os coeficientes de permeabilidade dos concretos permeáveis avaliados foram elevados, apresentando permeabilidade superior à mínima de 0,001 m/s, indicada pela NBR 16416 (ABNT, 2015), chegando a valores de $0,0064 \mathrm{~m} / \mathrm{s}$, apresentado pelo traço 3 .

Em relação a tração na flexão, todos os traços analisados apresentaram valores acima do mínimo exigido por norma, $2 \mathrm{MPa}$. No entanto, em relação aos ensaios destrutivos, nenhum traço atendeu aos requisitos mínimos de tração na flexão concomitantemente a resistência à compressão, que por sua vez precisaria ultrapassar o mínimo de 20 MPa, indicado pela NBR 16416 (ABNT, 2015).

A utilização de 5 e $10 \%$ de areia auxiliou de forma mais relevante nos traços, pois melhorou a resistência dos corpos de prova, porém apresentou grande influência na permeabilidade, mostrando uma adição peculiar nos seus valores. Para o traço 2, a verificação da ausência da areia se mostrou desfavorável quanto a resistência, e diferente do senso comum, também não apresentou melhoria no valor de permeabilidade. 
A utilização dos traços 1 e 3 apresentaram maior coerência à aplicação na construção de passeios urbanos, pisos internos, praças, quadras poliesportivas descobertas, ciclovias e até mesmo estacionamentos de veículos leves, auxiliando assim nos processos do sistema de drenagem presente. Porém, os mesmos ainda não são indicados para a construção de pavimentos de veículos urbanos ou rodoviários, devido ainda a baixa resistência a compressão axial, mesmo apresentando bons valores de tração na flexão. Para que seja liberada tal utilização ainda é necessário fazer o estudo sobre a eficiência de algumas adições na mistura para melhorar essa resistência e cumprir com os requisitos exigidos em norma.

\section{REFERÊNCIAS}

ABNT. Associação Brasileira de Normas Técnicas. NBR 5738: Moldagem e cura de corpos-de-prova de concreto cilíndricos ou prismáticos. Rio de Janeiro: ABNT, 2015.

ABNT. Associação Brasileira de Normas Técnicas. NBR 5739: Concreto - Ensaio de compressão de corpos-de-prova cilíndricos. Rio de Janeiro: ABNT, 1994

ABNT. Associação Brasileira de Normas Técnicas. NBR NM 248: Agregados - Determinação da composição granulométrica. Rio de Janeiro: ABNT, 2003.

ABNT. Associação Brasileira de Normas Técnicas. NBR NM 52: Agregado miúdo - Determinação da massa específica e massa específica aparente. Rio de Janeiro: ABNT, 2003.

ABNT. Associação Brasileira de Normas Técnicas. NBR NM 45: Agregados - Determinação da massa unitária e do volume de vazios. Rio de Janeiro: ABNT, 2006.

ABNT. Associação Brasileira de Normas Técnicas. NBR 15900-1: Água para amassamento do concreto - Parte 1: Requisitos. Rio de Janeiro: ABNT, 2009.

ABNT. Associação Brasileira de Normas Técnicas. NBR 12142: Concreto - Determinação da resistência à tração na flexão em corpos-de-prova prismáticos. Rio de Janeiro: ABNT, 2010.

ABNT. Associação Brasileira de Normas Técnicas. NBR 16416: Pavimentos permeáveis de concreto - Requisitos e procedimentos. Rio de Janeiro: ABNT, 2015.

ABNT. Associação Brasileira de Normas Técnicas. NBR 5738: Concreto - Procedimento para moldagem e cura de corpos de prova. Rio de Janeiro: ABNT, 2015.

BATEZINI, R.. Estudo preliminar de concretos permeáveis como revestimento de pavimentos para áreas de veículos leves. Dissertação (Mestrado Engenharia Civil) Universidade de São Paulo, São Paulo, 2013.

BOTTEON, L. M.. Desenvolvimento e caracterização de concreto permeável para utilização em blocos intertravados para estacionamentos. Monografia (Bacharelado) - Universidade Federal Fluminense, Niterói,
2017.

BU, J.; CHEN, X.; LIU, S.; LI, S.; SHEN, N.. Experimental study on the dynamic behavior of pervious concrete for permeable pavement. Computers and Concrete, v.22, n 3, p.291-303, 2018. DOI: http://dx.doi.org/10.12989/cac.2018.22.3.291

HANSEN, D. J.; ALLEN, H. E.. The importance of trace metal speciation to water quality criteria. Water Environment Research, v.68, n.1, p.42-54, 1996.

OLIVEIRA, C. G. M.. Estudo de propriedades mecânicas e hidráulicas do concreto asfáltico drenante. Dissertação (Mestrado em Engenharia) - Universidade de Brasília, Brasília, 2003.

SANTOS, K. A.; RUFINO, I. A. A.; BARROS FILHO, M. N. M.. Impactos da ocupação urbana na permeabilidade do solo: o caso de uma área de urbanização consolidada em Campina Grande/PB. Engenharia Sanitária Ambiental, v.22, n.5, p.943-952, 2017. DOI: http://doi.org/10.1590/S141341522016146661

SANTOS, R. R.; VIER, L. C.; BUENO, B. G.; HAMMES, R. F.; PEDROZO, E. C.. Estudo do Desempenho do Concreto Permeável com a Implantação de RCC. In: CONGRESSO REGIONAL DE INICIAÇÃO CIENTÍFICA E TECNOLÓGICA EM ENGENHARIA, 27. Anais. Ijuí, 2017.

SUMANASOORIYA, M. S.; NEITHALATH, N.. Pore structure features of pervious concretes proportioned for desired porosities and their performance prediction. Cement and Concrete Composites, v.33, n.8, p.778-787, 2011. DOI: http://doi.org/10.1016/i.cemconcomp.2011.06.002

TARGA, M. S.; BATISTA, G. T.; DINIZ, H. N.; DIAS, N. W.; MATOS, F. C.. Urbanização e escoamento superficial na bacia hidrográfica do Igarapé Tucunduba, Belém, PA, Brasil. Revista Ambiente \& Água: An Interdisciplinary Journal of Applied Science, v.7, n.2, 2012. DOI: http://dx.doi.org/10.4136/ambi-agua.905

ZHONG, R.; WILLE, K.. Linking pore system characteristics to the compressive behavior of pervious concrete. Cement and Concrete Composites, v.70, p.130-138, 2016.

A CBPC - Companhia Brasileira de Produção Científica (CNPJ: 11.221.422/0001-03) detém os direitos materiais desta publicação. Os direitos referem-se à publicação do trabalho em qualquer parte do mundo, incluindo os direitos às renovações, expansões e disseminacões da contribuicão, bem como outros direitos subsidiários. Todos os trabalhos publicados eletronicamente poderão posteriormente ser publicados em coletâneas impressas sob coordenação da Sustenere Publishing, da Companhia Brasileira de Produção Científica e seus parceiros autorizados. Os (as) autores (as) preservam os direitos autorais, mas não têm permissão para a publicação da contribuição em outro meio, impresso ou digital, em português ou em tradução. 